\title{
Attentional blink in adolescents with varying levels of impulsivity
}

\author{
Chiang-shan Ray Li ${ }^{\text {a,* }}$, Sue-Huei Chen ${ }^{\mathrm{b}}$, Wei-hao Lin ${ }^{\mathrm{a}}$, Yong-Yi Yang ${ }^{\mathrm{c}}$ \\ ${ }^{a}$ Brain and Behavior Laboratory, Medical Research Center, Chang Gung Memorial Hospital, Tao-Yuan, Taiwan \\ ${ }^{\mathrm{b}}$ Department of Psychology, National Taiwan University, Taipei, Taiwan \\ ${ }^{\mathrm{c}}$ Graduate Institute of Behavioral Science, Chang Gung University, Tao-Yuan, Taiwan
}

\begin{abstract}
We explore the temporal attention function in a non-clinical sample of adolescents varying in impulsivity, as assessed with the Barratt Impulsiveness Scale. In a Rapid Serial Visual Presentation task, in which two targets $\left(T_{1}\right.$ and $\left.T_{2}\right)$ were presented in close temporal proximity among distractors, participants tried to identify $T_{1}$ and detect $T_{2}$ in one (dual-task) experiment and only to detect $T_{2}$ in a second, control (single-task) experiment. The sensitivity of $T_{2}$ detection was analyzed using signal detection theory. The attentional blink - the impairment in $\mathrm{T}_{2}$ detection following the identification of $\mathrm{T}_{1}-$ was increased in magnitude and protracted in adolescents with high impulsivity, compared with those with low impulsivity. Moreover, a few more participants with high impulsivity appeared to have a blink temporally weighing toward a later time, an observation also made in children with attention deficit hyperactivity disorder (ADHD) in an earlier study. Taken together, these findings suggest impairment in temporal attention in adolescents with high impulsivity. As in ADHD children, a gating deficit may play a central role in this attention impairment. (C) 2004 Elsevier Ltd. All rights reserved.
\end{abstract}

Keywords: Attention; Temporal; Gating; Attentional blink; Impulsivity; ADHD

\section{Introduction}

Impulsivity is an important behavioral construct that has attracted considerable clinical attention (Allen et al., 1998; Askenazy et al., 2003; Barratt et al., 1999; Brady et al., 1998; Cools et al., 2003; Corruble et al., 2003; Corruble et al., 1999; Dougherty et al., 1999a,b; Dougherty et al., 2000; Hoptman et al., 2000; Kashden et al., 1993; Lejoyeux et al., 1998; Mulder et al., 1999; Soloff et al., 2003; Swann et al., 2000; Welch and Fairburn, 1996). Perhaps because of the wide range of behavioral conditions in which impulsivity is involved, current knowledge of the biological or psychological basis of

\footnotetext{
${ }^{*}$ Corresponding author. Present address: Department of Psychiatry, Yale University Connecticut Mental Health Center, Room S103 34 Park Street, New Haven, CT 06519, USA. Tel.: +1-203-974-7354; fax: +1-203-974-7366.

E-mail address: chiang-shan.li@yale.edu (C.-S. Ray Li).
}

impulsivity has drawn heavily on studies of psychiatric disorders in which impulsivity is manifested. In particular, as impulsivity is a core behavioral deficit in children with attention deficit hyperactivity disorder (ADHD), a myriad of studies have addressed impulsivity-related issues in this disorder (Babinski et al., 1999; Barkley, 1992; Burns and Walsh, 2002; Bussing et al., 2002; Chhabildas et al., 2001; Gomez, 2003; McKay and Halperin, 2001; Oades et al., 2002; Overtoom et al., 1998; Perchet et al., 2001; Retz et al., 2003; Rubia, 2002; Vitacco and Rogers, 2001).

Laboratory measures of impulsivity have mainly focused on two different but not mutually exclusive dimensions: inability to delay reward, leading to a tendency to choose immediate small rewards over larger delayed ones (Monterosso and Ainslie, 1999; Sagvolden et al., 1998; Solanto et al., 2001; Sonuga-Barke et al., 1992); and inability to withhold inappropriate response, leading to errors of commission on tests that require updating of response strategy based on contextual 
information. In the latter conceptual framework, many studies have reported an increased number of commission error (response to a non-target) in the Continuous Performance Test (CPT), for instance, as a measure of higher impulsivity (Corkum and Siegel, 1993; Dougherty et al., 1999b; Inoue et al., 1998; Klorman et al., 1988; Parasnis et al., 2003), although the specificity of this finding has been questioned in others (Barkley, 1992; Epstein et al., 2003; Thompson and Nichols, 1992; see also Riccio and Reynolds, 2001 for a review). Likewise, increased failures in withholding a response (response despite signal to stop) in a go/no-go or stop-signal task have been suggested to reflect impulsivity in ADHD or other psychiatric disorders (Brown et al., 1989; Dougherty et al., 2003; Horn et al., 2003; LeMarquand et al., 1999; Marinkovic et al., 2000; Oades et al., 2002; Trommer et al., 1991). Within a broader conceptual scheme, increased perseverative error in the Wisconsin Card Sorting Test (i.e., an error made when one continues to sort card according to an earlier rule despite having been told that the rule is incorrect) has been suggested to implicate defective inhibitory function, leading to premature decision and response in the patients (Gansler et al., 1998; Gorenstein et al., 1989; Houghton et al., 1999; Loge et al., 1990; Rapport et al., 2001; Reeve and Schandler, 2001; Wilding et al., 2001). Behavioral paradigms less structured than these neuropsychological tests have also been used to study impulsivity in ADHD. For instance, using a variant of Posner's cuing paradigm, Perchet and colleagues characterized the neurophysiological correlates of attentional shifting (Perchet et al., 2001). It was found that, compared to healthy participants, ADHD children demonstrated more anticipatory errors along with physiological evidence for deficient early perceptual processing. The results were suggested to implicate motor impulsivity in these children. In essence, these neuropsychological studies have looked for an experimental analogue of behavioral impulsivity. They have provided an objective measure of impulsivity and an important first step toward delineating the perceptual, attention and decision processes underlying impulsivity.

Here we adopt a slightly different approach to examine impulsivity in this study. We examine whether impulsivity is a consequence of impaired cognitive function; specifically, whether it is correlated with a deficit in temporal attention in the first place. One could hypothesize that defective temporal attention lead to inefficient and strenuous processing of information and individuals may have learned to adapt to this difficulty by moving attention away from the current task before channeling processed information for adequate actions. This premature switch from one cognitive agenda to another may thus manifest as behavioral impulsivity. We explore this issue in a non-clinical sample of adolescents by examining whether there is a correlation between selfreported impulsivity as assessed by the Barratt Impulsiveness Scale (BIS, Patton et al., 1995) and temporal attention function, as demonstrated in a rapid serial visual presentation (RSVP) paradigm.

The RSVP task has been used extensively in the literature to explore the temporal characteristics of information processing (Broadbent and Broadbent, 1987; Chun and Potter, 1995; Raymond et al., 1992; Reeves and Sperling, 1986; Shapiro et al., 1994; Ward and Duncan, 1996; Weichselgartner and Sperling, 1987; see also Shapiro et al., 1997 for a review) and, more recently, to examine attention deficits in people with neurological and psychiatric disturbances (Hollingsworth et al., 2001; Husain et al., 1997; Li et al., 2002; Li et al., 2004; Rizzo et al., 2001; Rokke et al., 2002). Fig. 1 illustrates a typical example of this behavioral paradigm, in which a series of stimuli are presented in rapid succession and the

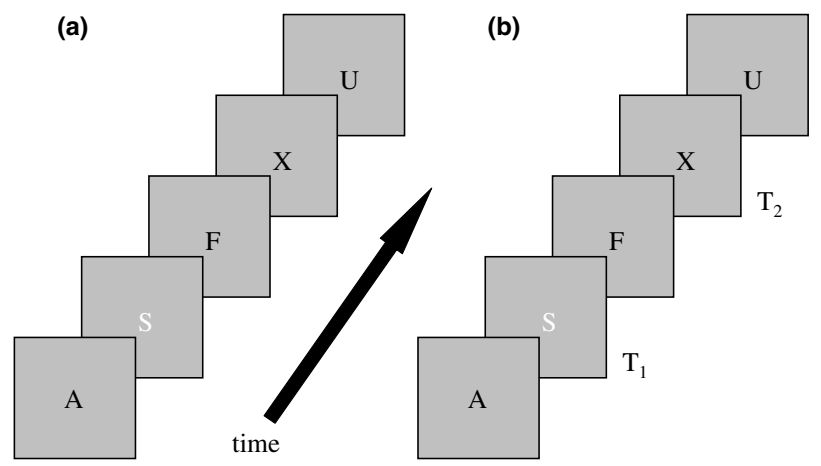

(c)

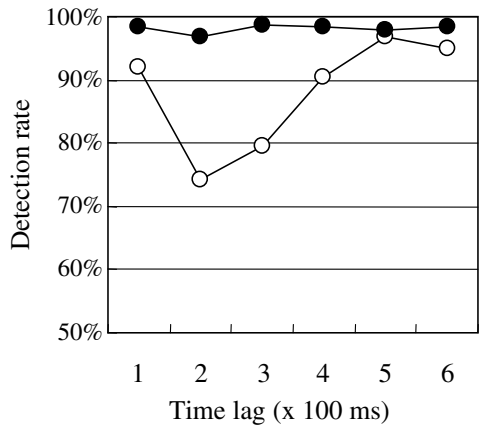

Fig. 1. A typical RSVP paradigm and attentional blink. (a) Singletarget task. A stream of characters appears rapidly one after another. The participant's task is to identify whether there is an " $\mathrm{X}$ " in the stream. (b) Dual-target task. The visual display is exactly the same as in the single-target task. The participant has to identify the character that appears brighter than the others $\left(\mathrm{T}_{1}\right.$, an " $\mathrm{S}$ " in this case) and then detect whether there is an " $X$ " $\left(T_{2}\right)$ in the characters that follow $T_{1}$. (c) Attentional blink. The detection rate of " $\mathrm{X}$ " in the single- (filled circles) and dual- (open circles) target task is plotted with respect to the time "lag" between $T_{1}$ and " $X$ ". Characteristically, the detection rate of " $X$ " in the dual-target task drops for a period of several hundred mseconds after the identification of $T_{1}$, compared to that in the singletarget task. 
participants are required to identify either one (control experiment) or two targets. In this example task the participants have to discriminate the first target and detect the presence of a specified character, X, under the dualtask condition. In the control, single-task condition, the participant is required only to detect the character $\mathrm{X}$. One can vary the task difficulty by adjusting the duration of presentation of the visual stimulus and by manipulating the physical similarity between the target and the distractors. With these parameters appropriately set, we are able to examine how attention and processing resources are temporally allocated to effectively deal with the rapidly changing inputs, by comparing the respective performances of the participants for each of the two task conditions.

Characteristically, when the participants are required to identify two targets (as compared to one target), an attentional "blink" in the processing of the second target or $T_{2}$ is observed for a few hundred milliseconds after the identification of the first target or $\mathrm{T}_{1}$ (Raymond et al., 1992; Fig. 1(c)). Two recent studies have employed this technique to examine the attention deficit in patients with ADHD (Hollingsworth et al., 2001; Li et al., 2004). Compared to healthy participants, the patients exhibited a deeper and wider attentional blink; namely, the blink is greater in magnitude and temporally more extended. Interestingly, some ADHD children appeared to have a blink quite normal in magnitude but temporally displaced toward a later time, a result that can be explained by a gating model of temporal attention ( $\mathrm{Li}$ et al., 2004). The primary goal of the current study is thus to demonstrate whether similar observations could be extended to a non-clinical sample of adolescents with higher level of impulsivity.

\section{Methods}

\subsection{Participants}

Written consent was obtained from all of the participants after the nature and the procedures of the study were explained in details, in strict accordance to the institute guidelines. Six hundred and sixty-two adolescents (325 males, 337 females; ages 15-17 years) from the Ho-Ping High School of the Taipei city completed screening with a Chinese version of the Barratt Impulsiveness Scale version 11 (BIS-11, Patton et al., 1995), the Maudsley Obsessive Compulsive Inventory (Hodgson and Rachman, 1977), the Buss-Perry Aggression Questionnaire (Buss and Perry, 1992) and the Children's Depression Inventory (Kovacs, 1985). The detailed psychometric properties of the Chinese versions of these scales will be presented in a separate work. The BIS-11 is a 30-item self-report questionnaire designed to measure impulsivity. All items are measured on a 4-point scale $\quad(1=$ rarely/never; $\quad 2=$ occasionally; $3=$ often; $4=$ almost always/always). The total score thus ranges from 30 to 120, with a higher score indicating higher impulsivity. Eleven of the 30 items are scored in a reverse order to avoid response bias. The BIS-11 has been translated into Italian and Japanese with good internal consistency and test-retest reliability (Fossati et al., 2001; Someya et al., 2001). The Chinese version employed in the current study also demonstrated good internal consistency with a Cronbach's $\alpha$ of 0.81 .

Screening was conducted over a period of two hours on a school day with the permission of the school authority. The total impulsivity score of all 662 participants ranged from 47 to 108 (mean \pm standard deviation: $72.5 \pm 8.7$ ) and appeared to follow a normal distribution (Fig. 2). We developed a selection sequence of the subjects based on their impulsivity score and gender and planned to recruit 32 subjects (16 males and 16 females) each with the lowest, intermediate and highest impulsivity score to further take part in the attentional blink study. For a variety of personal reasons, many of them declined to participate. Toward the end of the study period, we had 20 ( 9 males, $17.0 \pm 1.2$ years; 11 females, $17.2 \pm 0.9$ years), 31 (14 males, $16.2 \pm 1.7$ years; 17 females, $16.3 \pm 1.4$ years $)$ and 18 (8 males, $16.5 \pm 1.5$ years; 10 females, $17.3 \pm 0.5$ years) of the children with low (mean \pm standard deviation: $56.8 \pm 3.1$ ), intermediate $(72.4 \pm 1.1)$ and high $(91.6 \pm 4.1)$ impulsivity scores, respectively, who completed the behavioral task. There is no difference in age or gender composition between the three groups. Fifteen of the 20 subjects in the low impulsivity group had their total impulsivity score one and a half standard deviations lower than the average, and all of them in the high impulsivity group had a total score two standard deviations above the average. All of the participants had normal or corrected-to-normal vision. They also denied ever having seizure, brain injury, or been seen by a psychiatrist.

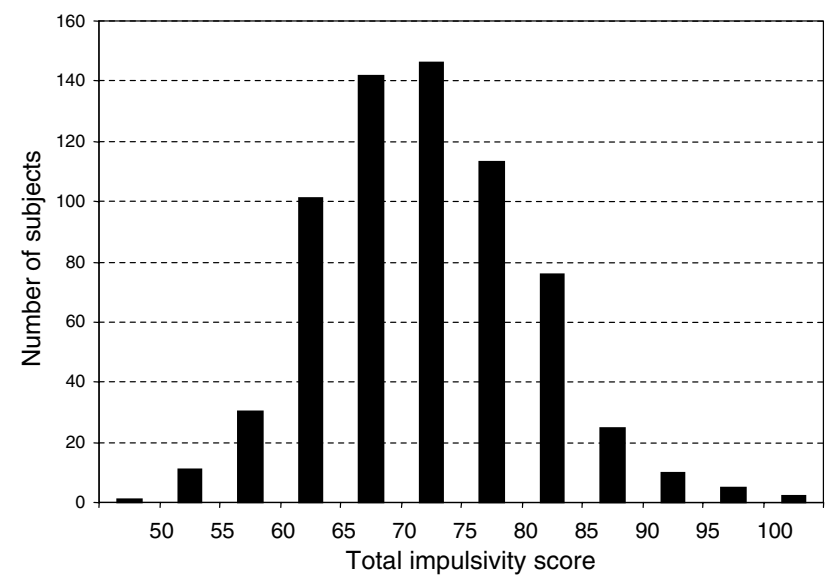

Fig. 2. The distribution of the total BIS-11 score of our 662 subjects. The total impulsivity score was binned every five points. 


\subsection{Test setting, behavioral task and experimental procedures}

The testing took place in an interview room at the Department of Psychology, National Taiwan University. Although the room was not sound proof, the setting was quiet and free of interruptions. Only the participant and the person who administered the test were allowed in the room. The test was in most cases conducted on a weekend or a holiday and any time during the day.

In the RSVP task, the visual stimuli, consisting of 34 Chinese phonological characters and six Arabic numerals $(2-7)$, were presented in rapid succession at the location of visual fixation (Fig. 3). Each trial consisted of 14 to 22 stimuli, one of which was a number. Each stimulus was presented for $33 \mathrm{~ms}$ with an interstimulus interval of $67 \mathrm{~ms}$. The number was preceded by anywhere from 7 to 15 characters and followed by 6 more in a trial. In one experiment (dual-task condition), the participants had to identify the number $\left(T_{1}\right)$ by pressing the appropriate number key on the computer keyboard. They also had to decide whether there was an "X-like" character (XLC, $\mathrm{T}_{2}$ ) following the number and rate subjective confidence in the accuracy of their response on a 5-point scale, again by pressing the appropriate number key on the computer keyboard: "1" for "absolutely sure that there was no XLC", and " 5 " for "absolutely sure that there was an XLC." Therefore, in the dual-task condition, the subjects answered two questions at their

$$
\begin{aligned}
& \text { (a) 万, П, ᄃ, 劢, 去, 了, 功, 《, 万, 厂, ᄂ, く, }
\end{aligned}
$$

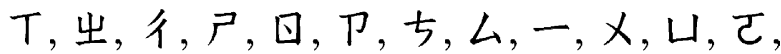

$$
\begin{aligned}
& \text { さ, せ, 万, 入, «, ろ, ム, 九, ᄂ, 儿 }
\end{aligned}
$$

(b)

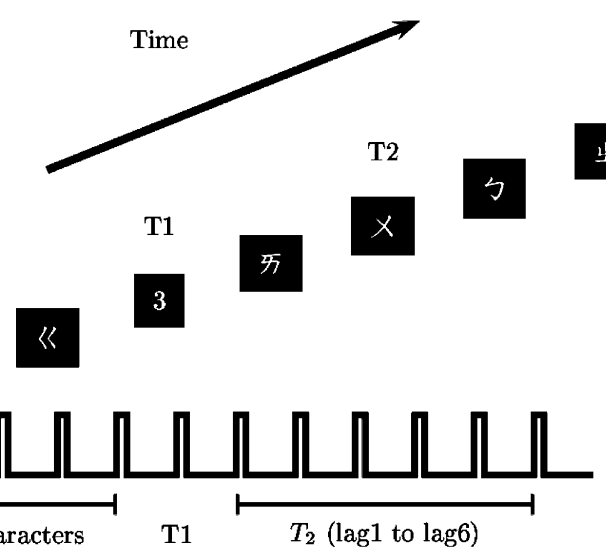

Fig. 3. The stimulus set (a) and RSVP task (b). Chinese phonological characters and Arabic numbers were presented on the basis of one stimulus per $0.1 \mathrm{~s}$ (stimulus duration $=33.3 \mathrm{~ms}$; inter-stimulus inter$\mathrm{val}=66.7 \mathrm{~ms}$ ). The Arabic number was brightened. In the dual-task condition, the participants identified the number first and detected an "X-like" character (XLC), which could appear anywhere from lag-1 to lag-6. In a control experiment, the participants ignored the number and tried only to detect the XLC. own pace by pressing appropriate keys on the keyboard at the end of each trial. The XLC appeared in half of the trials pseudorandomly at one of the six serial positions ("lags") following the number, with each position repeated 20 times in an experiment. In a second, control, experiment (single-task condition), participants were instructed to ignore the number and only to detect the XLC. They thus answered only one question in the single-task condition. The visual stimuli and test settings were otherwise the same in the two task conditions. Participants pressed the space bar to initiate a trial at their own pace and took approximately $80 \mathrm{~min}$ to complete the test.

The detection sensitivity for the XLC was computed for each time lag using receiver operating characteristic (ROC) analysis based on signal detection theory (Macmillan and Creelman, 1991). Because the boundary between response categories (" 1 " for absolutely sure and " 2 " for relatively confident, for instance) was not clear-cut and the data set we collected for each subject was relatively small, we employed the algorithm developed by Metz and Pan to properly estimate the ROC curves (Metz and Pan, 1999; http://www-radiology.uchicago. edu/krl/KRL_ROC/ROC_analysis_by_topic. htm\#PROPROC). A deterioration of the detection sensitivity of XLC in the dual-task compared to the singletask condition has been termed an "attentional blink" (Raymond et al., 1992). The attentional blink was thus a measure of how the performance in detecting the second target had been affected by the additional task of having to identify the first target. The attentional blink could be quantified on two aspects: overall magnitude and temporal profile. The former was derived by summing up the decrease in detection sensitivity at each individual time lag and the latter represented the pattern of altered sensitivity over a time period of $600 \mathrm{~ms}$ examined in the current study.

\section{Results}

\subsection{General Performance in the RSVP task}

The three groups correctly identified the number $\left(\mathrm{T}_{1}\right)$ in $90.9 \pm 5.9 \%$ (mean \pm standard deviation, low impulsivity), $89.5 \pm 5.6 \%$ (intermediate impulsivity), and $87.7 \pm 7.3 \%$ (high impulsivity) of the trials, which were not statistically different $\left(F_{2,66}=1.345, \quad p=0.268\right.$, one-way ANOVA). Post hoc comparisons showed no difference between any two groups, either. This result suggested all three groups of participants were adequately engaged in this attention task, which made it possible to compare their performance in the identification of $\mathrm{T}_{2}$ between single- and dual-task conditions (i.e., attentional blink). We also computed response bias (in units of root-mean-squared standard deviation, with a 
negative value indicating a positive bias) for each participant (Macmillan and Creelman, 1991). A response-bias index is to measure the subject's willingness to say "yes"; i.e., to say that they are (very) confident that there is an $\mathrm{X}$-like character following $\mathrm{T}_{1}$. A response-bias index is therefore a monotonic function of both the hit and false-alarm and can be formulated based on different bias statistics (Macmillan and Creelman, 1991). The results showed that the response bias did not differ between the three groups (mean \pm standard deviation: $-0.32 \pm 0.45$, low impulsivity; $-0.23 \pm 0.51$, intermediate impulsivity; $-0.09 \pm 0.43$, high impulsivity; $F_{2,66}=1.163, p=0.319$, one-way ANOVA)

\subsection{Attentional blink}

Fig. 4 plots the $T_{2}$ detection sensitivity across the 6 time lags both for the single- and dual-task conditions. We derived for all three groups of participants the attentional blink by subtracting the sensitivity in the dual-task condition from that in the single-task condition. The results from a repeated measures ANOVA with time lag as the within-subject variable and group as the betweensubject variable showed that the three groups differed in the magnitude of attentional blink $\left(F_{2,66}=4.251\right.$, $p=0.018$, group main effect). The group $\times$ lag interaction was not significant $\left(F_{8.5,281.5}=1.361, p=0.209\right.$, Greenhouse-Geisser correction), suggesting that the difference between groups did not vary with time lag. Post hoc comparisons show that there was a group main effect between the high and low impulsivity groups $\left(F_{1,36}=\right.$ $9.606, p=0.004)$, with group $\times$ lag interaction approaching statistical significance $\left(F_{3.8,136.6}=2.143, p=0.082\right.$, Greenhouse-Geisser correction). On the other hand, there was no difference between the high and intermediate impulsivity groups either in main effect $\left(F_{1,47}=2.323\right.$, $p=0.134)$ or in group $\times$ lag interaction $\left(F_{4.2,197.1}=\right.$ 1.447, $p=0.218$, Greenhouse-Geisser correction) and between the intermediate and low impulsivity groups either in main effect $\left(F_{1,49}=2.806, p=0.100\right)$ or in group $\times$ lag interaction $\left(F_{3.4,168.5}=0.405, \quad p=0.776\right.$, Greenhouse-Geisser correction). Overall, these results showed that the magnitude of attentional blink appeared to increase in participants with higher impulsivity score. Also, the difference in the blink magnitude might vary with time lag when high and low impulsivity groups were compared.

Despite the relatively small sample size, we explored if there was a gender effect on attentional blink. A repeated measures ANOVA with time lag as the within-subject variable and group and gender as the between-subject variables showed that the group effect was significant $\left(F_{2,63}=3.849, p=0.026\right)$, but not gender $\left(F_{1,63}=1.377\right.$, $p=0.245$ ) or any of the two-way or the three-way interactions. Another repeated measures ANOVA limited to the data set with only high and low impulsivity subjects revealed essentially the same results, showing significant group effect $\left(F_{1,34}=9.217, p=0.005\right)$ but not significant gender $\left(F_{1,34}=2.905, p=0.097\right)$ or interaction effects.

We examined the temporal profile of attentional blink in each individual participant. While the majority of participants had a blink that peaked at earlier time lags, some (particularly those in the high impulsivity group) had the blink weighing toward later time lags. To quantify this observation, we computed for each individual participant the magnitude of the blink for an early time period, comprising lag- 1 to lag-3, and a late time period comprising lag-4 to lag-6. A participant was considered to be an "early blinker" if there was a larger decrease in the detection sensitivity in the early time period and a "late blinker" if the reverse applied. The results showed that there were 17 and 3 early and late blinkers in the low impulsivity group, 25 early and 6 late blinkers in the intermediate impulsivity group, and 11 early and 7 late blinkers in the high impulsivity group. We examined for a difference in this frequency measure between groups in a hierarchical log-linear model with the group and blink period (early and late) as categorical variables. The results showed that there (a)

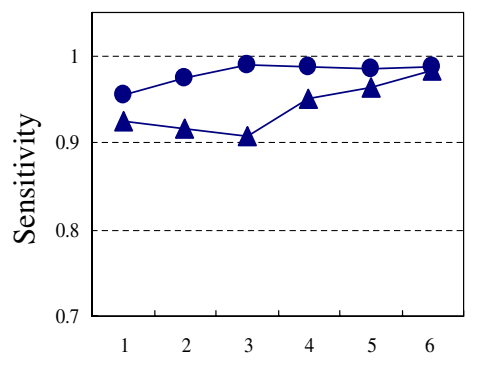

(b)

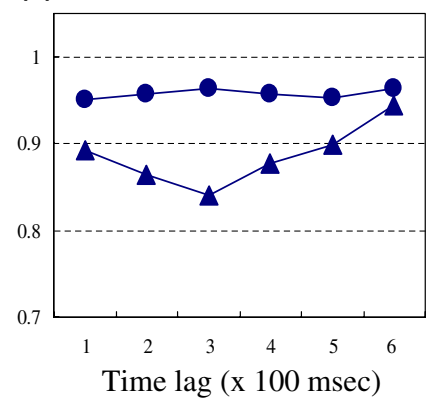

(c)

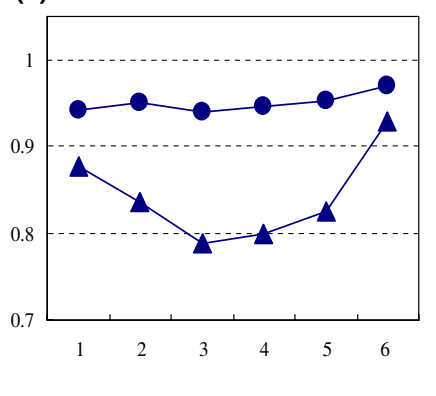

Fig. 4. $T_{2}$ detection sensitivity in low (a), intermediate (b) and high (c) impulsivity group. Data are presented separately for the one-target (circle) and two-target (triangle) task and for each time lag. Each data point represents an average across all participants in the group. High-impulsivity participants demonstrate a blink larger in magnitude and protracted than the low-impulsivity participants. Please see text for statistics. 
was a significant blink period main effect (partial $\chi^{2}=20.921, p<0.000$ ), suggesting that there were overall more early blinkers. However, the group $\times$ blink period interaction was not significant (partial $\chi^{2}=3.305$, $p=0.192$ ), suggesting that there was no difference in blink patterns among the three groups of participants.

\section{Discussion}

A number of models have been proposed to explain attentional blink and they share common characteristics (Chun and Potter, 1995; Shapiro et al., 1997). According to a two-stage model, the attentional blink is the result of a limited-capacity second stage in which targets detected in the first stage are processed and consolidated serially (Chun and Potter, 1995). When the duration of this limited-capacity processing of $T_{1}$ exceeds the stimulus onset asynchrony between $T_{1}$ and $T_{2}$, interference with the processing of $T_{2}$ occurs. This deficit suggests an intrinsic limitation of our central nervous system to deal with rapidly changing stimuli, highlighting the serial aspect of attentional function. An increased and protracted attentional blink thus suggests a less efficient processing mechanism in our subjects with high impulsivity when they have to deal with rapidly changing inputs. Moreover, more high impulsivity subjects have an attentional blink temporally displaced toward later time lags, compared to other participants. Overall, these results are similar to those obtained in children with ADHD in an earlier study (Li et al., 2004). This finding perhaps is not surprising given that impulsivity is a core behavioral deficit in children with ADHD.

To account for these findings, we have proposed an attention-gating model, in which a gate controls the flow of information from a perceptual buffer to a level where the cognitive processing required for target detection and identification takes place ( $\mathrm{Li}$ et al., 2004). Since processing capacity is limited, attention gating facilitates perceptual and cognitive processing by allowing only an adequate amount of information to access this level at a given time. In this conceptual framework, a deficit or blink occurs when the processing resources are not available or when incoming stimuli saturate those processing resources. An attentional blink occurs also when the temporal mechanism of gating is altered. As in the ADHD children, high-impulsivity subjects of the current study appear to have a slower dynamics of gating, with more stimuli flowing in the second stage of processing. As a result, those subjects without adequate resources to process the extra "bits" of information would demonstrate a deeper and wider blink. On the other hand, those with more resources would be able to process the additional information and demonstrate not just lag-1, but also lag-2 or perhaps even lag-3, sparing. As a result, they would demonstrate a blink with a rela- tively normal magnitude but temporally displaced toward later time lags. Therefore, when compared to those with low impulsivity, high-impulsivity subjects as a group showcase a profile of attentional blink displaced toward a later time.

The relationship between behavioral impulsivity and attention function has mostly been examined in terms of the performance of ADHD children in the CPT (see Barkley, 1992; Corkum and Siegel, 1993; for reviews). A recent study attempted to ascertain the specificity of sustained attention deficits in CPT in children with ADHD (Swaab-Barneveld et al., 2000). The results showed that sustained attention deficit was to a certain extent common to children with a variety of different psychiatric disorders. These sustained attention tests are thus sensitive but lacking in specificity in relation to ADHD participants (Riccio and Reynolds, 2001). The current study examines the relationship between impulsivity and attention function from a slightly different perspective. Our RSVP task concentrates on temporal control in attentional processing within a relatively short time scale. This paradigm thus explores a more restrictive aspect of attention function, compared to the CPTs and our results indexed a deficit in temporal attention in high-impulsivity individuals. It is important to note that the deeper and wider attentional blink as is observed in high-impulsivity subjects has also been observed in patients with dyslexia, with schizophrenia, and with depression, as well as in patients with focal brain lesions (Hari et al., 1999; Husain et al., 1997; Li et al., 2002; Li and Lin, unpublished results; Rizzo et al., 2001; Rokke et al., 2002). An increased attentional blink is thus not a finding specific to high impulsivity; instead, it may simply reflect limited processing capacity, which could occur in a variety of CNS conditions. On the other hand, our preliminary results on the altered temporal profile in attention blink in high-impulsivity subjects suggest that temporal dynamics is an important aspect of attention function that deserves further investigation.

There are a few important limitations in the current study. First, our subjects did not undergo a formal neurological or psychiatric examination; nor did they receive an IQ test or any other neuropsychological assessments. An IQ score would have been an important factor to examine in evaluating the current results. It is particularly relevant in view of the attention gating model, since an IQ score would have been a useful indicator of general processing resources in each individual subject. Likewise, we did not drug-screen or obtain a complete medication history of our subjects. We could thus not rule out the possibility that impaired performance in the high impulsivity subjects resulted from their use of medication or illicit substances. Finally, the small sample size has greatly limited the statistical power of the current study. Further work with a larger number of subjects will be required to replicate the current find- 
ings and to examine whether the temporal profile of attentional blink indeed differs between high and low impulsivity subjects and whether gender plays a role in determining these results.

\section{Acknowledgements}

We thank all of the students who participated in our study and the school authority for its facility. We are grateful to Dr. Ernest Barratt for allowing us to translate BIS-11 into Chinese for this work. We also thank Ya-Ping Lee for carrying out the questionnaire interviews and Sue-Yee Lin, Chuan-Hwa Wang, Mei-Hui Lee, Shu-Hwa Chu, and Chun-Han Liang for carrying out some of the experiments. This study is supported by grants from the Chang Gung Memorial Hospital. Finally, we greatly appreciate the comments and suggestions of three anonymous reviewers of this study. Please address correspondence to: Dr. Chiang-shan Ray Li, who is now at Connecticut Mental Health Center, Room S103, Department of Psychiatry, Yale University, 34 Park Street, New Haven, CT 06519. E-mail: chiang-shan.li@yale.edu.

\section{References}

Allen TJ, Moeller FG, Rhoades HM, Cherek DR. Impulsivity and history of drug dependence. Drug and Alcohol Dependence 1998;50:137-45.

Askenazy FL, Sorci K, Benoit M, Lestideau K, Myquel M, Lecrubier $\mathrm{Y}$. Anxiety and impulsivity levels identify relevant subtypes in adolescents with at-risk behavior. Journal of Affective Disorder 2003;74:219-27.

Babinski LM, Hartsough CS, Lambert NM. Childhood conduct problems, hyperactivity-impulsivity, and inattention as predictors of adult criminal activity. Journal of Child Psychology and Psychiatry 1999;40:347-55.

Barkley RA. The ecological validity of laboratory and analogue assessment methods of ADHD symptoms. Journal of Abnormal Child Psychology 1992;19:49-178.

Barratt ES, Stanford MS, Dowdy L, Liebman MJ, Kent TA. Impulsive and premeditated aggression. A factor analysis of selfreported acts. Psychiatry Research 1999;86:163-73.

Brady KT, Myrick H, McElroy S. The relationship between substance use disorders, impulse control disorders, and pathological aggression. American Journal of Addiction 1998;7:221-30.

Broadbent DE, Broadbent MHP. From detection to identification: response to multiple targets in rapid serial visual presentation. Perception and Psychophysics 1987;42:105-13.

Brown D, Fenwick P, Howard R. The contingent negative variation in a Go/No Go avoidance task: relationships with personality and subjective state. International Journal of Psychophysiology 1989;7:35-45.

Burns GL, Walsh JA. The influence of ADHD-hyperactivity/impulsivity symptoms on the development of oppositional defiant disorder symptoms in a 2-year longitudinal study. Journal of Abnormal Child Psychology 2002;30:245-56.

Buss AH, Perry M. The aggression questionnaire. Journal of Personality and Social Psychology 1992;63:452-9.
Bussing R, Grudnik J, Mason D, Wasiak M, Leonard C. ADHD and conduct disorder: an MRI study in a community sample. World Journal of Biological Psychiatry 2002;3:216-20.

Chhabildas N, Pennington BF, Willcutt EG. A comparison of the neuropsychological profiles of the DSM-IV subtypes of ADHD. Journal of Abnormal Child Psychology 2001;29:529-40.

Chun MM, Potter MC. A two-stage model for multiple target detection in rapid serial visual presentation. Journal of Experimental Psychology: Human Perception and Performance 1995;21:109-27.

Cools R, Barker RA, Sahakian BJ, Robbins TW. L-Dopa medication remediates cognitive inflexibility, but increases impulsivity in patients with Parkinson's disease. Neuropsychologia 2003;41: 1431-41.

Corkum PV, Siegel LS. Is the Continuous Performance Task a valuable research tool for use with children with Attention-DeficitHyperactivity Disorder?. Journal of Child Psychology and Psychiatry 1993;34:1217-39.

Corruble E, Damy C, Guelfi JD. Impulsivity: a relevant dimension in depression regarding suicide attempts?. Journal of Affective Disorder 1999;53:211-5.

Corruble E, Benyamina A, Bayle F, Falissard B, Hardy P. Understanding impulsivity in severe depression? A psychometrical contribution. Progress in Neuropsychopharmacollogy and Biological Psychiatry 2003;27:829-33.

Dougherty DM, Bjork JM, Harper RA, Marsh DM, Moeller FG, Mathias $\mathrm{CW}$, et al. Behavioral impulsivity paradigms: a comparison in hospitalized adolescents with disruptive behavior disorders. Journal of Child Psychology and Psychiatry 2003;44:1145-57.

Dougherty DM, Bjork JM, Huckabee HC, Moeller FG, Swann AC. Laboratory measures of aggression and impulsivity in women with borderline personality disorder. Psychiatry Research 1999a;85: 315-26.

Dougherty DM, Bjork JM, Marsh DM, Moeller FG. A comparison between adults with conduct disorder and normal control subjects on a Continuous Performance Test: differences in impulse response characteristics. Psychological Record 2000;50:203-19.

Dougherty DM, Moeller FG, Steinberg JL, Marsh DM, Hines SE, Bjork JM. Alcohol increases commission error rates for a continuous performance test. Alcoholism, Clinical and Experimental Research 1999b;23:1342-51.

Epstein JN, Erkanli A, Conners CK, Klaric J, Costello JE, Angold A. Relations between Continuous Performance Test performance measures and ADHD behaviors. Journal of Abnormal Child Psychology 2003;31:543-54.

Fossati A, Di Ceglie A, Acquarini E, Barratt ES. Pscyhometric properties of an Italian version of the Barratt Impulsiveness Scale11 (BIS-11) in nonclinical subjects. Journal of Clinical Psychology 2001;57:815-28.

Gansler DA, Fucetola R, Krengel M, Stetson S, Zimering R, Makary C. Are there cognitive subtypes in adult attention deficit/hyperactivity disorder? Journal of Nervous and Mental Disease 1998;186:776-81.

Gomez R. Underlying processes in the poor response inhibition of children with Attention-Deficit/Hyperactivity Disorder. J Atten Disord 2003;6:111-22.

Gorenstein EE, Mammato CA, Sandy JM. Performance of inattentive-overactive children on selected measures of prefrontal-type function. Journal of Clinical Psychology 1989;45:619-32.

Hari R, Valta M, Uutela K. Prolonged attentional dwell time in dyslexic adults. Neuroscience Letters 1999;271:202-4.

Hodgson RJ, Rachman S. Obsessional-compulsive complaints. Behaviour Research and Therapy 1977;15:389-95.

Hollingsworth DE, McAuliffe SP, Knowlton BJ. Temporal allocation of visual attention in adult attention deficit hyperactivity disorder. Journal of Cognitive Neuroscience 2001;13: 298-305. 
Hoptman MJ, Volavka J, Johnson G, Weiss E, Bilder RM, Lim KO. Frontal white matter microstructure, aggression, and impulsivity in men with schizophrenia: a preliminary study. Biological Psychiatry 2000;52:9-14.

Horn NR, Dolan M, Elliott R, Deakin JF, Woodruff PW. Response inhibition and impulsivity: an fMRI study. Neuropsychologia 2003;41:1959-66.

Houghton S, Douglas G, West J, Whiting K, Wall M, Langsford S, et al. Differential patterns of executive function in children with attention-deficit hyperactivity disorder according to gender and subtype. Journal of Child Neurology 1999;14:801-5.

Husain M, Shapiro K, Martin J, Kennard C. Abnormal temporal dynamics of visual attention in spatial neglect patients. Nature 1997;385:154-6.

Inoue K, Nadaoka T, Oiji A, Morioka Y, Totsuka S, Kanbayashi Y, et al. Clinical evaluation of attention-deficit hyperactivity disorder by objective quantitative measures. Child Psychiatry and Human Development 1998;28:179-88.

Kashden J, Fremouw WJ, Callahan TS, Franzen MD. Impulsivity in suicidal and nonsuicidal adolescents. Journal of Abnormal Child Psychology 1993;21:339-53.

Klorman R, Brumaghim JT, Salzman LF, Strauss J, Borgstedt AD, McBride MC, et al. Effects of methylphenidate on attention-deficit hyperactivity disorder with and without aggressive/noncompliant features. Journal of Abnormal Psychology 1988;97:413-22.

Kovacs M. The Children's Depression Inventory (CDI). Psychopharmacology Bulletin 1985;21:995-8.

Lejoyeux M, Feuche N, Loi S, Solomon J, Ades J. Impulse-control disorders in alcoholics are related to sensation seeking and not to impulsivity. Psychiatry Research 1998;81(2):149-55.

LeMarquand DG, Benkelfat C, Pihl RO, Palmour RM, Young SN. Behavioral disinhibition induced by tryptophan depletion in nonalcoholic young men with multigenerational family histories of paternal alcoholism. American Journal of Psychiatry 1999;156:1771-9.

Li C-SR, Lin W-H, Yang YY, Huang CC, Chen YC, Chen TW. Impairment of temporal attention in patients with schizophrenia. Neuroreport 2002;13:1427-30.

Li C-SR, Lin W-H, Chang H-L, Hung Y-W. A psychophysical measure of attention deficit in children with attention deficit hyperactivity disorder. Journal of Abnormal Psychology 2004;113:228-36.

Loge DV, Staton RD, Beatty WW. Performance of children with ADHD on tests sensitive to frontal lobe dysfunction. Journal of the American Academy of Child and Adolescent Psychiatry 1990;29:540-5.

McKay KE, Halperin JM. ADHD, aggression, and antisocial behavior across the lifespan. Interactions with neurochemical and cognitive function. Annals of New York Academy of Sciences 2001;931:84-96.

Macmillan NA, Creelman CD. Detection theory: a user's guide. Cambridge (MA): Cambridge University Press; 1991.

Marinkovic K, Halgren E, Klopp J, Maltzman I. Alcohol effects on movement-related potentials: a measure of impulsivity? Journal of Studies on Alcohol 2000;61:24-31.

Metz CE, Pan X. "Proper" binormal ROC curves: theory and maximum-likelihood estimation. Journal of Mathematical Psychology 1999;43:1-33.

Monterosso J, Ainslie G. Beyond discounting: possible experimental models of impulse control. Psychopharmacology (Berlin) 1999; 146:339-47.

Mulder RT, Joyce PR, Sullivan PF, Bulik CM, Carter FA. The relationship among three models of personality psychopathology: DSM-III-R personality disorder, TCI scores and DSQ defences. Psychological Medicine 1999;29:943-51.

Oades RD, Slusarek M, Velling S, Bondy B. Serotonin platelettransporter measures in childhood attention-deficit/hyperactivity disorder (ADHD): clinical versus experimental measures of impulsivity. World Journal of Biological Psychiatry 2002;3:96-100.

Overtoom CC, Verbaten MN, Kemner C, Kenemans JL, van Engeland H, Buitelaar JK, Camfferman G, Koelega HS. Associations between event-related potentials and measures of attention and inhibition in the Continuous Performance Task in children with ADHD and normal controls. Journal of the American Academy of Child and Adolescent Psychiatry 1998;37:977-85.

Patton JH, Stanford MS, Barratt ES. Factor structure of the Barratt Impulsiveness Scale. Journal of Clinical Psychology 1995;51:768-74.

Parasnis I, Samar VJ, Berent GP. Deaf adults without attention deficit hyperactivity disorder display reduced perceptual sensitivity and elevated impulsivity on the Test of Variables of Attention (T.O.V.A.). Journal of Speech Language and Hearing Research 2003;46:1166-83.

Perchet C, Revol O, Fourneret P, Mauguiere F, Garcia-Larrea L. Attention shifts and anticipatory mechanisms in hyperactive children: an ERP study using the Posner paradigm. Biological Psychiatry 2001;50:44-57.

Rapport LJ, Van Voorhis A, Tzelepis A, Friedman SR. Executive functioning in adult attention-deficit hyperactivity disorder. Clinical Neuropsychology 2001;15:479-91.

Raymond JE, Shapiro KL, Arnell KM. Temporary suppression of visual processing in an RSVP task: an attentional blink?. Journal of Experimental Psychology: Human Perception and Performance 1992;18:849-60.

Reeve WV, Schandler SL. Frontal lobe functioning in adolescents with attention deficit hyperactivity disorder. Adolescence 2001;36: 749-65.

Reeves A, Sperling G. Attention gating in short-term visual memory. Psychological Review 1986;93:180-206.

Retz W, Rosler M, Supprian T, Retz-Junginger P, Thome J. Dopamine D3 receptor gene polymorphism and violent behavior: relation to impulsiveness and ADHD-related psychopathology. Journal of Neural Transmission 2003;110:561-72.

Riccio CA, Reynolds CR. Continuous performance tests are sensitive to ADHD in adults but lack specificity. Annals of the New York Academy of Science 2001;931:113-39.

Rizzo M, Akutsu H, Dawson J. Increased attentional blink after focal cerebral lesions. Neurology 2001;57:795-800.

Rokke PD, Arnell KM, Koch MD, Andrews JT. Dual-task attention deficits in dysphoric mood. Journal of Abnormal Psychology 2002;111:370-9.

Rubia K. The dynamic approach to neurodevelopmental psychiatric disorders: use of fMRI combined with neuropsychology to elucidate the dynamics of psychiatric disorders, exemplified in ADHD and schizophrenia. Behavioural Brain Research 2002;130:47-56.

Sagvolden T, Aase H, Zeiner P, Berger D. Altered reinforcement mechanisms in attention-deficit/hyperactivity disorder. Behavioural Brain Research 1998;94:61-71.

Shapiro KL, Arnell KM, Raymond JE. The attentional blink. Trends in Cognitive Science 1997;1:291-6.

Shapiro KL, Raymond JE, Arnell KM. Attention to visual pattern information produces the attentional blink in RSVP. Journal of Experimental Psychology: Human Perception and Performance 1994;20:357-71.

Solanto MV, Abikoff H, Sonuga-Barke E, Schachar R, Logan GD, Wigal $\mathrm{T}$, et al. The ecological validity of delay aversion and response inhibition as measures of impulsivity in AD/HD: a supplement to the NIMH multimodal treatment study of AD/HD. Journal of Abnormal Child Psychology 2001;29: 215-28.

Soloff PH, Meltzer CC, Becker C, Greer PJ, Kelly TM, Constantine D. Impulsivity and prefrontal hypometabolism in borderline personality disorder. Psychiatry Research 2003;123:153-63. 
Someya T, Sakado K, Seki T, Kojima M, Reist C, Tang SW, Takahashi S. The Japanese version of the Barratt Impulsiveness Scale, 11th version (BIS-11): its reliability and validity. Psychiatry and Clinical Neuroscience 2001;55:111-4.

Sonuga-Barke EJ, Taylor E, Sembi S, Smith J. Hyperactivity and delay aversion - I. The effect of delay on choice. Journal of Child Psychology and Psychiatry 1992;33:387-98.

Swaab-Barneveld H, de Sonneville L, Cohen-Kettenis P, Gielen A, Buitelaar J, Van Engeland H. Visual sustained attention in a child psychiatric population. Journal of American Academy of Child and Adolescent Psychiatry 2000;39:651-9.

Swann AC, Anderson J, Dougherty DM, Moeller FG. Measurement of interepisode impulsivity in bipolar disorder: preliminary report. Psychiatry Research 2000;101:195-7.

Thompson RW, Nichols GT. Correlations between scores on a continuous performance test and parents' ratings of attention problems and impulsivity in children. Psychological Reports 1992;70:739-42.
Trommer BL, Hoeppner JA, Zecker SG. The go-no go test in attention deficit disorder is sensitive to methylphenidate. Journal of Child Neurology 1991;6(Suppl.):S128-31.

Vitacco MJ, Rogers R. Predictors of adolescent psychopathy: the role of impulsivity, hyperactivity, and sensation seeking. Journal of American Academy of Psychiatry an the Law 2001;29:374-82.

Ward R, Duncan J. The slow time-course of visual attention. Cognitive Psychology 1996;30:79-109.

Weichselgartner E, Sperling G. Dynamics of automatic and controlled visual attention. Science 1987;238:778-80.

Welch SL, Fairburn CG. Impulsivity or comorbidity in bulimia nervosa. A controlled study of deliberate self-harm and alcohol and drug misuse in a community sample. British Journal of Psychiatry 1996;169:451-8.

Wilding J, Munir F, Cornish K. The nature of attentional differences between groups of children differentiated by teacher ratings of attention and hyperactivity. British Journal of Psychology 2001;92:357-71. 